\title{
The evolution of myocardium at risk by T2-STIR MR imaging the first week after acute myocardial ischemia
}

David Nordlund ${ }^{1 *}$, Gert Klug², Einar Heiberg ${ }^{1,3}$, Sasha Koul ${ }^{4}$, Terje H Larsen ${ }^{5,6}$, Pavel Hoffmann ${ }^{9}$, Bernhard Metzler ${ }^{2}$, David Erlinge ${ }^{4}$, Dan Atar ${ }^{7}$, Anthony H Aletras ${ }^{1,8}$, Marcus Carlsson ${ }^{1}$, Henrik Engblom ${ }^{1}$, Håkan Arheden ${ }^{1}$

From 19th Annual SCMR Scientific Sessions

Los Angeles, CA, USA. 27-30 January 2016

\section{Background}

Myocardial salvage is currently being used as endpoint in several clinical trials and is determined by relating final infarct size to myocardium at risk (MaR). T2-weighted imaging (T2-STIR) cardiac magnetic resonance (CMR) has previously been shown to enable assessment of MaR up to one week after acute myocardial infarction. Recent experimental data indicate that the extent of $\mathrm{MaR}$ by T2-STIR varies over the first week which would have implications on how to design clinical cardioprotection trials using myocardial salvage as endpoint and in the clinical diagnosis of patients with myocardial infarction and
To investigate whether MaR as assessed by T2-STIR differs depending on scan day during the first week after the acute event in patients with reperfused first-time myocardial infarction.

\section{Methods}

196 STEMI-patients from the MITOCARE and CHILLMI trials undergoing acute percutaneous coronary intervention were included in the study. Eight additional patients with CMR on day 1 were also included. T2-STIR MR imaging was performed 1-7 days after the acute event and was used to evaluate MaR. Diagnostic quality on a
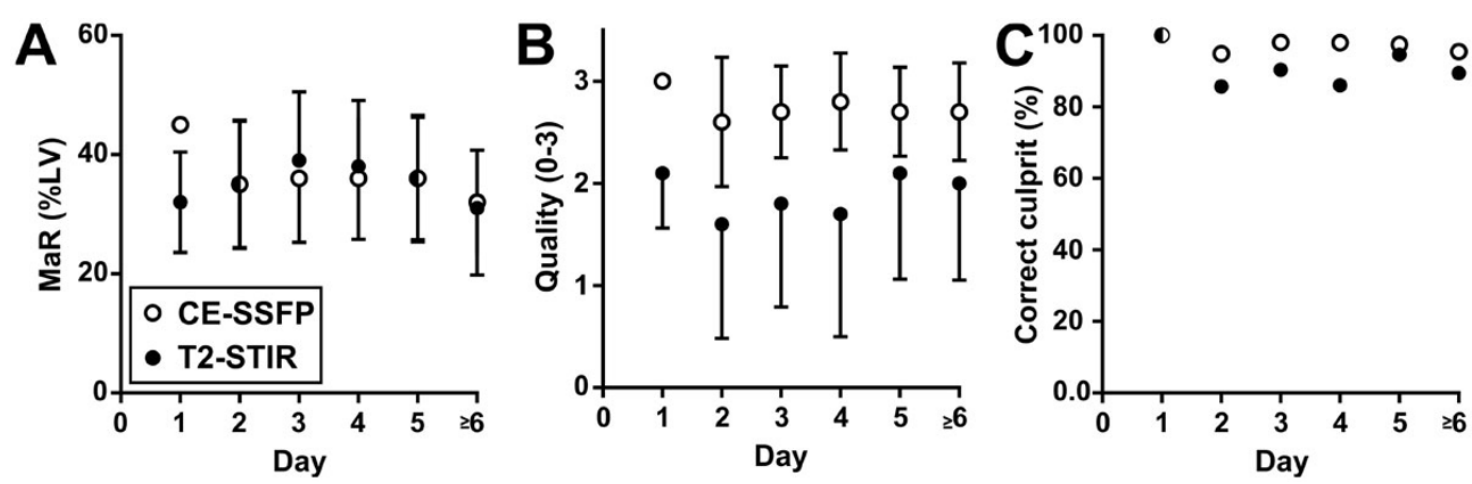

Figure 1 MaR by T2-STIR over the first week. A) MaR as \% of LV mass over time; B) diagnostic image quality over time; and C) Ratio of correctly assigned culprit vessel compared to angiography over time. Note that there is no significant change in MaR during the first week in any of the above aspects. Open and closed circles show mean values of MaR by CE-SSFP and T2-STIR respectively. Error bars show 1 standard deviation. MaR=Myocardium at risk, LV=Left ventricular mass, T2-STIR= T2-weighted short tau inversion recovery, $C E-S S F P=$ contrast enhanced steady state free precession, LGE=late gadolinium enhancement.

normal coronary arteries.

'Department of Clinical Physiology, Clinical Sciences, Lund University, Lund,

Sweden

Full list of author information is available at the end of the article

(c) 2016 Nordlund et al. This is an Open Access article distributed under the terms of the Creative Commons Attribution License (http:// 
scale from 0-3 and ability to correctly assign culprit vessel compared to angiography.

\section{Results}

There was no significant difference in $\mathrm{MaR}$ over the first week $(\mathrm{p}=0.44$, Figure $1 \mathrm{~A})$ neither was there any change in diagnostic quality $(p=0.26$, Figure $1 B)$. The rate of correctly assigned culprit vessel was also similar for the different scan days (Figure 1C).

\section{Conclusions}

Myocardium at risk by T2-STIR CMR imaging do not change in humans over the first week after acute reperfused myocardial infarction suggesting that MaR is a stable measure during this period of time.

\section{Authors' details}

'Department of Clinical Physiology, Clinical Sciences, Lund University, Lund, Sweden. ${ }^{2}$ University Clinic of Internal Medicine III, Cardiology and Angiology, Medical University of Innsbruck, Innsbruck, Austria. ${ }^{3}$ Department of

Biomedical Engineering, Faculty of Engineering, Lund University, Lund,

Sweden. ${ }^{4}$ Department of Cardiology, Clinical Sciences, Lund University, Lund, Sweden. ${ }^{5}$ Department of Heart Disease, Haukeland University Hospital,

Bergen, Norway. ${ }^{6}$ Department of Biomedicine, University of Bergen, Bergen, Norway. ${ }^{7}$ Department of Cardiology B, Oslo University Hospital Ullevål and University of Oslo, Oslo, Norway. ${ }^{8}$ Laboratory of Medical Informatics, School of Medicine, Aristotle University of Thessaloniki, Thessaloniki, Greece. ${ }^{9}$ Section for Interventional Cardiology, Department of Cardiology, Oslo University Hospital, Ullevål, Oslo, Norway.

Published: 27 January 2016

Cite this article as: Nordlund et al:: The evolution of myocardium at risk by T2-STIR MR imaging the first week after acute myocardial ischemia. Journal of Cardiovascular Magnetic Resonance 2016 18(Suppl 1):P94.

Submit your next manuscript to BioMed Central and take full advantage of:

- Convenient online submission

- Thorough peer review

- No space constraints or color figure charges

- Immediate publication on acceptance

- Inclusion in PubMed, CAS, Scopus and Google Scholar

- Research which is freely available for redistribution

Submit your manuscript at www.biomedcentral.com/submit 